\title{
A new clupeid fish from the upper Miocene of Greece: A possible Hilsa relative from the Mediterranean
}

Charalampos Kevrekidis, Gloria Arratia, Nikos Bacharidis, and Bettina Reichenbacher Acta Palaeontologica Polonica 66 (3), 2021: 605-621 doi:http://dx.doi.org/10.4202/app.00871.2020

Much remains to be learned about the past diversity and evolutionary history of the Clupeidae (herrings, shads and allies), owing to the frequently subtle differences between modern taxa and the moderate preservational quality of some fossils. In this study, new clupeid fossils are described from a new locality from the upper Miocene of the Serres Basin, Northern Greece. The fossils are well-preserved articulated skeletons, exhibiting features such as a small size ( 